\title{
PENGEMBANGAN BUKU AJAR EKONOMI INDONESIA DENGAN MENGINTERNALISASIKAN NILAI-NILAI KEINDONESIAAN PROGRAM STUDI PENDIDIKAN EKONOMI IKIP BUDI UTOMO
}

\author{
Novi Eko Prasetyo ${ }^{1}$, Miftah Rakhmadian ${ }^{2}$ \\ 1,2 Fakultas Ilmu Sosial dan Humaniora, IKIP Budi Utomo Malang \\ e-mail: enopi79@gmail.com
}

\begin{abstract}
The focus of developing this Indonesian economic textbook is to internalize the character of Indonesian values, Indicators of Indonesian values include; nationalism, love for the motherland and democracy. Achievement of learning is demonstrated by the ability to conduct in-depth study of economic problems in Indonesia, as well as the activity and critical thinking skills of students in the learning process. Indonesian economic textbooks are presented with the scope of contextual problems so that students can analyze issues related to Indonesia's economic conditions. The aim of the Indonesian economic textbook is to reconstruct the concept between theory and practice by internalizing Indonesian values. The discussion in each subject becomes the main point of planting the character of Indonesian values. The research method used is R \& D (Research and Development). The teaching book material consists of 7 subjects, each of which has internalized the Indonesian values.
\end{abstract}

Keywords: Indonesian economic, textbook

\section{PENDAHULUAN}

Aspek yang dikaji dalam buku ekonomi Indonesia adalah Dasar-Dasar perekonomian menurut Pancasila dan UUD 1945, Dinamika kebijakan fiskal dan moneter, masalah pengangguran, pembangunan ekonomi, sektor pangan dan otonomi daerah. Permasalahan dari sektor sosial ekonomi membuat perubahan arah pendidikan dan pembelajaran ekonomi yang membawa proses kemampuan berpikir kritis dan kemampuan pemecahan masalah-masalah yang ada. Kemampuan berpikir kritis mendorong siswa untuk berperan aktif dalam pembelajaran (Malcom, N. L. 2006). Harapannya literasi yang di peroleh mahasiswa setelah mempelajari buku ini adalah literasi digital, literasi analisis dan literasi data. Literasi digital dikemas dengan informasi terkini, tepat waktu, dinamis, menarik sesuai dengan karakter mahasiswa pada abad 21 serta dapat melatih siswa berfikir kritis melalui bentuk kolaborasi pembelajaran online (Staff. 2013, Fitzhenry, S., \& Wilkens, K. 2017, Hart, T., Bird, D., \& Farmer, R. 2019). Aspek lain yang dapat di pelajari adalah aspek budaya-perekonomian daerah. Buku teks setidaknya menggambarkan hubungan budaya dan antar budaya hal ini berfungsi sebagai langkah penting mencegah siswa mencapai perspektif global (Pei I Chou, dkk 2019).

Program Studi Pendidikan Ekonomi IKIP Budi Utomo Malang, mulai mengembangkan buku-buku ajar yang sesuai dengan kurikulum dan visi-misi nya. 
Ekonomi Indonesia menjadi salah satu matakuliah wajib dan masuk di kriteria matakuliah Keilmuan dan Keterampilan (MKK), kode matakuliah Ekonomi Indonesia adalah EKO209. Karakter keindonesiaan yang di terapkan dalam Tri Dharma (Pendidikan dan Pengajaran, Penelitian dan Pengabdian) perguruan tinggi adalah ciri khas IKIP Budi Utomo.

Indikator dari nilai-nilai keindonesiaan meliputi; nasionalisme, demokrasi dan cinta tanah air. Nasionalisme merupakan wujud rasa cinta tanah air dan bangsa atas dasar kesadaran dan rasa tanggung jawab sebagai warga negara (Kusumawardani, A., \& Faturochman, M. A. 2004). Hal ini dapat diimplementasikan melalui peraturan-peraturan pemerintah yang menjunjung tinggi rasa keadilan sosial, Manajemen sumberdaya alam untuk kemakmuran dan kemaslahatan masyarakat, serta dapat menjaga harmonisasi hubungan kerjasama antar negara. Salah satu bentuk kerjasama disini adalah internasionalisasi perguruan tinggi; melalui program pertukaran pelajar, kolaborasi peneliti antar negara dan program beasiswa luar negeri hal ini dapat meningkatkan harmonisasi hubungan antar negara (Khalid, J., Ali, A. J., Nordin, N. M., \& Shah, S. F. H. 2019).

Demokrasi di Indonesia menurut bung Hatta (1966) dalam buku "demokrasi kita" adalah semangat kebersamaan dan kekeluargaan, wujud dari kebersamaan itu meliputi sikap saling tolong menolong, gotong royong, serta musyawarah untuk mencapai mufakat. Sistem demokrasi di Indonesia menjadi pegangan pemerintah dalam penetapan kebijakan sehingga masyarakat dapat memperoleh rasa keadilan. Terdapat nilai-nilai demokrasi dalam dunia pendidikan, antara lain; nilai kesetaraan, menghargai hak asasi manusia, nilai keberagaman, nilai keadilan, sikap toleransi, kemanusiaan, ketertiban, kebebasan dan kemakmuran (Rahman, M. 2018). Hal inilah yang menjadi alasan bagi peneliti untuk menyusun Buku ajar Ekonomi Indonesia yang menginternalisasikan nilai-nilai Keindonesiaan.

\section{METODE PENELITIAN}

Jenis penelitian dan pengembangan yang digunakan oleh peneliti adalah R\&D (Research and Development), penelitian ini diterapkan pada mahasiswa jurusan pendidikan ekonomi IKIP Budi Utomo, data yang dikumpulkan berupa data primer berupa kuisioner yang diperoleh dari mahasiswa, informan pendukung adalah dosen serumpun pada Jurusan Pendidikan Ekonomi dan narasumber materi, media dan bahasa. Sumber data pendukung berupa catatan, rekaman, dan bahan lainnya yang relevan dengan penelitian ini. Tahapan dalam rancangan penelitianya sebagai berikut: 


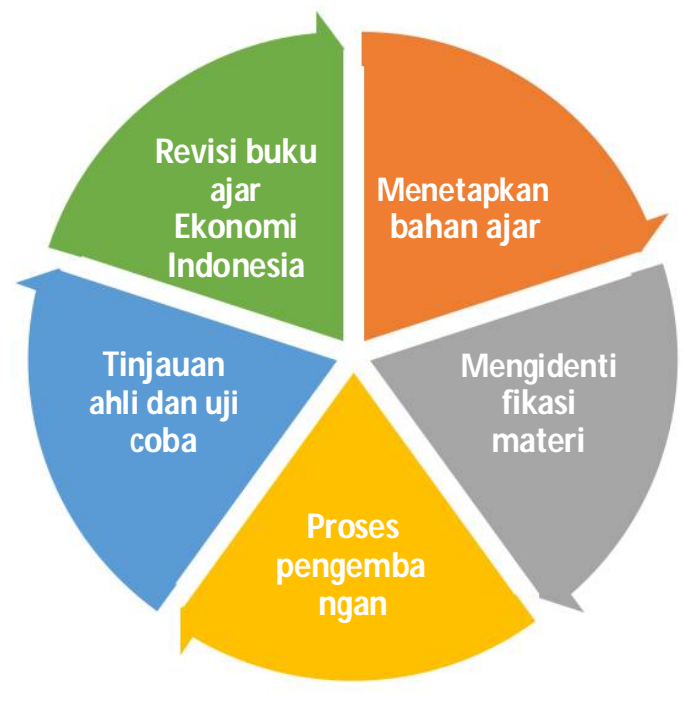

Gambar 1.

Rancangan Penelitian

Sumber: Data yang Diolah Peneliti

Kegiatan pengembangan buku ajar Ekonomi Indonesia ini, melalui 5 tahapan, yaitu;

1. Penetapan bahan ajar; Buku ajar ekonomi indonesia yang berisikan teori dan praktek dengan menginternalisasikan karakter nilai-nilai keindonesiaan pada mahasiswa Prodi Pendidikan Ekonomi.

2. Identifikasi materi; Menentukan pokok bahasan dan menetapkan isi atau materi beserta contoh-contoh isu/permasalahannya pada matakuliah ekonomi indonesia.

3. Proses pengembangan; Pada tahap ini langkah yang dilakukan, yaitu: (a) mengidentifikasi tujuan instruksional umum, (b) mengenali masukan, karakteristik dan ciri mahasiswa, (c) Menganalisis materi matakuliah Ekonomi Indonesia, (d) Merumuskan tujuan khusus, (e) mengembangkan strategi instruksional dan mengembangkan buku ajar Ekonomi Indonesia.

4. Tinjauan ahli dan uji coba; Buku ajar ekonomi Indonesia ini menggunakan tiga tahap kajian atau uji ahli, yaitu: (1) ahli materi, ahli media dan ahli bahasa Uji coba dilakukan pada mahasiswa melalui; (1) uji coba kelompok kecil (2) uji coba kelompok besar.

5. Revisi buku ajar Ekonomi Indonesia; Perbaikan buku ajar ekonomi Indonesia di dasarkan pada hasil kajian FGD oleh para Dosen, reviuwer tim Ahli dan Uji Mahasiswa. 


\section{HASIL DAN PEMBAHASAN}

Hasil dari penelitian dan pengembangan buku ajar ekonomi Indonesia terdiri dari beberapa tahapan:
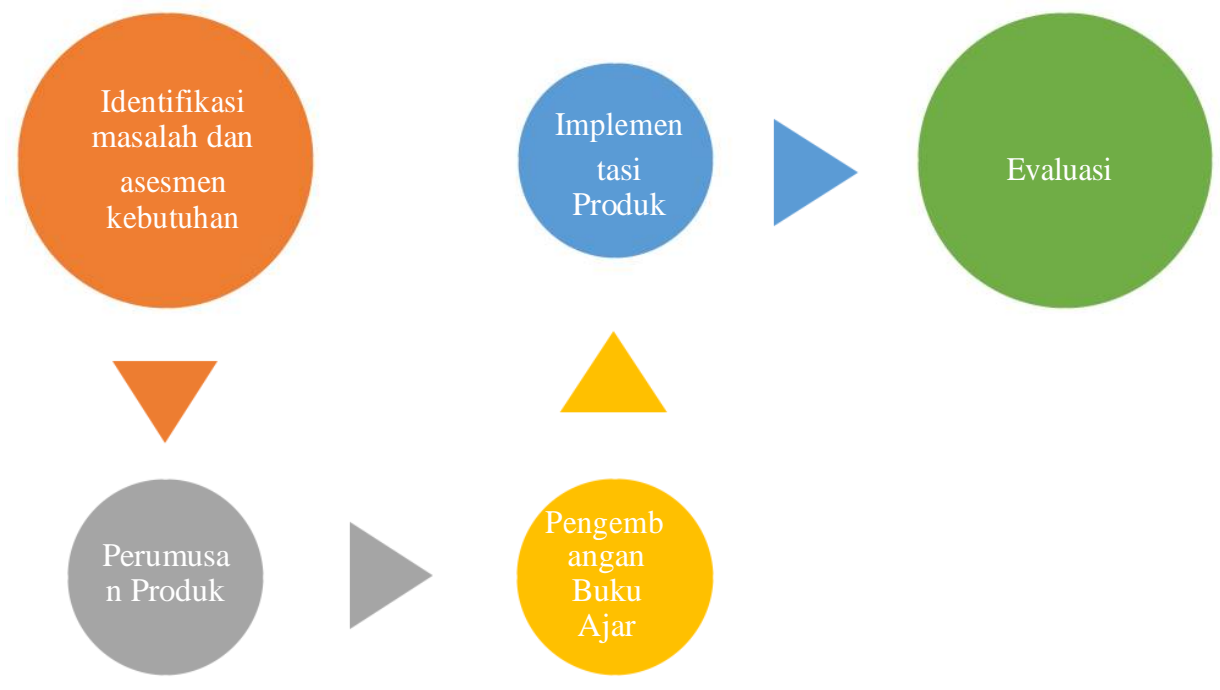

Gambar 2.

Paparan Tahapan Pengembangan

Sumber: Data yang Diolah Peneliti

1. Identifikasi masalah dan asesmen kebutuhan pembelajaran pada matakuliah ekonomi Indonesia Program Studi S1 Pendidikan Ekonomi IKIP Budi Utomo Malang. Hal-hal yang dianalisis meliputi:

a) Berdasarkan kajian literatur; Buku Ajar ekonomi Indonesia yang selama ini sudah ada belum sesuai dengan kurikulum program studi pendidikan ekonomi yang didalamnya menanamkan karakter nilai-nilai keindonesiaan.

b) Berdasarkan analisa kebutuhan Dosen Pengampu; Kesulitan dalam menentukan topik pembelajaran yang dapat membentuk karakter pada diri mahasiswa sehingga dibutuhkan buku ajar ekonomi indonesia yang menginternalisasikan karakter nilai-nilai keindonesian.

c) Berdasarkan analisa kebutuhan mahasiswa; mahasiswa masih kesulitan mencari sumber literatur yang relevan dengan topik pembelajaran yang disajikan.

2. Perumusan buku Ajar ekonomi Indonesia, peneliti melakukan FGD dengan para Dosen dan tim ahli (ahli materi, ahli media dan ahli bahasa) merumuskan pokok bahasan yang menginternalisasikan karakter nilai-nilai ke Indonesiaan.

3. Penyusunan desain dan pengembangan buku ajar, setelah didapatkan materi umum yang akan dibahas maka selanjutnya peneliti menentukan Indikator materi buku ajar Ekonomi Indonesia. 
Tabel 1.

Materi Ekonomi Indonesia

\begin{tabular}{|c|c|c|}
\hline NO & Materi & Indikator \\
\hline 1 & $\begin{array}{l}\text { Dasar-Dasar } \\
\text { Perekonomian Menurut } \\
\text { Pancasila Dan UUD } 1945\end{array}$ & $\begin{array}{l}\text { Makna Sistem Ekonomi Pancasila } \\
\text { Makna Pasal } 33 \text { UUD } 1945\end{array}$ \\
\hline 2 & $\begin{array}{l}\text { Dinamika Kebijakan } \\
\text { Fiskal Indonesia }\end{array}$ & $\begin{array}{l}\text { Kebijakan Fiskal Dalam Perekonomian } \\
\text { Indonesia } \\
\text { Teori Kebijakan Fiskal } \\
\text { Tujuan Kebijakan Fiskal } \\
\text { Bentuk-Bentuk Kebijakan Fiskal Yang } \\
\text { Menginternalisasikan Nilai-Nilai Keindonesiaan } \\
\text { Macam-Macam Kebijakan Anggaran/ Fiskal }\end{array}$ \\
\hline 3 & $\begin{array}{l}\text { Bank Sentral Dan Sektor } \\
\text { Perbankan }\end{array}$ & $\begin{array}{l}\text { Kedudukan Bank Indonesia (BI) } \\
\text { Tujuan Dan Tugas Bank Indonesia Sebagai } \\
\text { Wujud Internalisasi Nilai-Nilai Keindonesiaan } \\
\text { Tugas Bank Indonesia } \\
\text { Peranan Bank Indonesia Dalam Pengendalian } \\
\text { Inflasi }\end{array}$ \\
\hline 4 & $\begin{array}{l}\text { Pengangguran, } \\
\text { Kemiskinan Dan } \\
\text { Ketimpangan Ekonomi }\end{array}$ & $\begin{array}{l}\text { Pengangguran } \\
\text { Kemiskinan } \\
\text { Ketimpangan Ekonomi }\end{array}$ \\
\hline 5 & $\begin{array}{l}\text { Infrasruktur Dan Iklim } \\
\text { Investasi }\end{array}$ & $\begin{array}{l}\text { Pembangunan Infrastruktur } \\
\text { Reformasi Birokrasi } \\
\text { Investasi }\end{array}$ \\
\hline 6 & $\begin{array}{l}\text { Kedaulatan Pangan } \\
\text { Nasional }\end{array}$ & $\begin{array}{l}\text { Sektor Pertanian Indonesia } \\
\text { Kendala Perkembangan Sektor Pertanian }\end{array}$ \\
\hline 7 & $\begin{array}{l}\text { Pembangunan Ekonomi } \\
\text { Daerah }\end{array}$ & $\begin{array}{l}\text { Ekonomi Daerah } \\
\text { Permasalahan Dalam Pembangunan Ekonomi } \\
\text { Daerah } \\
\text { Peran Pemerintah Dalam Pembangunan } \\
\text { Ekonomi Daerah } \\
\text { Paradigma Baru Dalam Pembangunan Ekonomi } \\
\text { Daerah } \\
\text { Strategi Dalam Pembangunan Ekonomi Daerah }\end{array}$ \\
\hline
\end{tabular}

J urnal Pendidikan IImu Sosial, Vol 29, No.2, Desember 2019,

p-ISSN: 1412-3835; e-ISSN: 2541-4569 
4. Implementasi diujiakan kepada tim ahli (ahli media, ahli materi dan ahli bahasa), hasilnya validasi ahli materi mendapatkan nilai 5 dengan kategori "sangat layak", validasi ahli media mendapatkan nilai 4 dengan kategori "layak", validasi ahli bahasa mendapatkan nilai 4 dengan kategori "layak", semua pengujian tersebut dilakukan dengan menggunakan skala linier antara 1 s/ d 5 . Implementasi dilakukan ke lebih dari 50 mahasiswa, hasil penilaian mahasiswa rata-rata $80 \%$ buku ajar ekonomi Indonesia ini "sangat baik".

Tabel 2.

Indikator Penilaian oleh Tim Ahli

\begin{tabular}{|c|c|c|}
\hline No & Tim Ahli & Indikator Penilaian \\
\hline \multirow{7}{*}{1} & & Kejelasan Indikator dengan isi materi \\
\hline & & Kejelasan Tujuan Pembelajaran \\
\hline & & Kejelasan penyajian materi di buku ekonomi \\
\hline & Ahli Materi & Indonesia \\
\hline & & Kelengkapan materi \\
\hline & & Kesesuaian konsep materi pelajaran \\
\hline & & Pengevaluasian materi \\
\hline & & $\begin{array}{l}\text { Kemenarikan tampilan fisik buku ekonomi Indonesia } \\
\text { Ketepatan penqqunaan desain buku }\end{array}$ \\
\hline \multirow[t]{3}{*}{2} & Ahli Media & Kejelasan paparan materi \\
\hline & & Kesesuaian teks cerita \\
\hline & & Kesesuaian penempatan bagian-bagian materi \\
\hline \multirow{6}{*}{3} & & Kejelasan bahasa yang dipakai \\
\hline & & Ketepatan penggunaan bahasa dalam penyajian \\
\hline & Ahli Bahasa & materi \\
\hline & & Kejelasan penggunaan EYD \\
\hline & & Ketepatan penggunaan tanda baca \\
\hline & & Kesesuaian alur cerita \\
\hline
\end{tabular}

5. Evaluasi yang dilakukan oleh ahli materi, ahli media, ahli bahasa, dosen bidang studi dan mahasiswa, diperoleh hal-hal sbb; 1) Perkaya refrensi sehingga materi yang disajikan lebih variatif. 2) Desain buku ajar harus lebih interaktif.

\section{KESIMPULAN}

Buku ajar ekonomi Indonesia yang dikembangkan dalam penelitian ini merupakan wujud internalisasi karakter nilai-nilai keindonesiaan yang meliputi; nasionalisme, demokrasi, dan cinta tanah air. Metode yang digunakan adalah R\&D. Hasil validasi ahli materi mendapatkan nilai "sangat layak", validasi ahli media mendapatkan nilai "layak", validasi ahli bahasa mendapatkan nilai "layak" dan Uji yang dilakukan oleh mahasiswa diperoleh nilai rata-rata "sangat baik". Hal tersebut menunjukkan bahwa buku ajar ekonomi Indonesia sebagai wujud nilainilai keindonesiaan layak digunakan dan dapat dijadikan referensi atau rujukan oleh Mahasiswa Program Studi Pendidikan Ekonomi. 


\section{DAFTAR PUSTAKA}

Basri, Faisal. 2002. Perekonomian Indonesia. Jakarta: Erlangga.

Boediono. 2016. Ekonomi Indonesia. Bandung: Mizan.

Chou, P.-I., Wang, Y.-T., \& Wu, S.-T. 2019. Content analysis of core concepts of global competence in junior high school English textbooks in Taiwan: Taking the content domains of the cognitive tests in the PISA 2018 global competence assessment as a framework. Journal of Textbook Research, 12(1), 1-38.

Fitzhenry, S., \& Wilkens, K. 2017. Supermoons Cause Tidal Waves! School Library Journal, 63(6), 20-21. Retrieved from http:/ / search.ebscohost.com/ login.aspx?direct=true\&AuthType=cookie,ip,s hib\&db=lfh\&AN=123266666\&site=lrc-live\&scope=site.

Gunadi, Tom. 1981. Sistem Perekonomian Menurut Pancasila dan UUD 45. Bandung: Angkasa.

Hart, T., Bird, D., \& Farmer, R. 2019. Using blackboard collaborate, a digital web conference tool, to support nursing student's placement learning: A pilot study exploring its impact. Nurse Education in Practice, 38, 72-78. doi:http:/ / dx.doi.org/ 10.1016/j.nepr.2019.05.009.

Hatta. 1966. Demokrasi Kita. Jakarta. Pustaka Antara.

Khalid, J., Ali, A. J., Nordin, N. M., \& Shah, S. F. H. 2019. Regional cooperation in higher education: Can it lead ASEAN toward harmonization? Southeast Asian Studies, 8(1), 81-98. doi:http:/ / dx.doi.org/10.20495/ seas.8.1_81.

Kusumawardani, A., \& Faturochman, M. A. 2004. Nasionalisme. Buletin Psikologi, 12(2).

Lan, T. J., \& Manan, M. A. (Eds.). 2011. Nasionalisme dan Ketahanan Budaya di Indonesia: Sebuah Tantangan. Yayasan Pustaka Obor Indonesia. https:/ / books.google.co.id/ books?hl=id\&lr=\&id=30irDAAAQBAJ\&oi=fnd\&p $\mathrm{g}=\mathrm{PA} 1 \& \mathrm{dq}=$ nasionalisme+indonesia\&ots=RxTk6rJJSA\&sig=ukg_uFpUHz5T VlZex5Jph1zBIC8\&redir_esc=y\#v=onepage\&q=nasionalisme\%20indonesia $\& f=$ false.

Malcom, N. L. 2006. Analyzing The News: Teaching Critical Thinking Skills in A Writing Intensive Social Problems Course. Teaching Sociology, 34(2), 143149. doi:http:/ / dx.doi.org/ 10.1177/ 0092055X0603400204

Manddaremmeng A. 2017. Transformasi Perekonomian Indonesia. Jakarta: Yayasan Pustaka Obor. 
Pigome, M. 2011. Implementasi Prinsip Demokrasi dan Nomokrasi dalam Struktur Ketatanegaraan RI Pasca Amandemen UUD 1945.Jurnal Dinamika Hukum, 11(2),

335-348. http:/ / dinamikahukum.fh.unsoed.ac.id/index.php/JDH/ article/ view/191/1 $\underline{39}$.

Purwanto, B. 2001. Memahami Kembali Nasionalisme Indonesia. Jurnal Ilmu Sosial dan Politik, 4. http:// i-lib.ugm.ac.id/jurnal/ detail.php?dataId=9863.

Rahman, M. 2018. Demokrasi Dalam Filsafat Pendidikan Barat Dan Islam (Kajian Tentang Nilai-Nilai Demokrasi Dan Implementasinya Dalam Konteks Pendidikan Indonesia). CENDEKIA: Jurnal Studi Keislaman, 3(2).

Staff. 2013. Digital Literacy. School Library Journal, 59(8), 62. Retrieved from http:/ / search.ebscohost.com/ login.aspx?direct=true\&AuthType=cookie,ip,s hib\&db=lfh\&AN=89564941\&site=lrc-live\&scope=site.

Swasono, S.E. 2009. Keparipurnaan Ekonomi Pancasila: Menegakkan Ekonomi Pancasila. Makalah untuk kongres Pancasila Kerjasama Universitas Gadjah Mada dan Mahkamah Konstitusi UGM, Yogyakarta, 30 Mei-1 Juni.

Swasono, 2012. Meluruskan Penyelewengan Mandat Konstitusi Pancasila Nasionalisme Pasal 33 UUD 1945 Menolak Neoliberalisme. Makalah untuk Kuliah Umum di Universitas Negeri Malang (dan Lembaga Pendidikan Lain di Sekitar Malang), Malang, 4 Juli. 